\title{
Hierarchically Porous ZSM-5 Synthesized by Nonionic- and Cationic-Templating Routes and Their Catalytic Activity in Liquid-Phase Esterification
}

\author{
R.R. Mukti ${ }^{1,2}$, Y. Kamimura ${ }^{1}$, W. Chaikittisilp ${ }^{1}$, H. Hirahara ${ }^{1}$, A. Shimojima ${ }^{1}$, M.

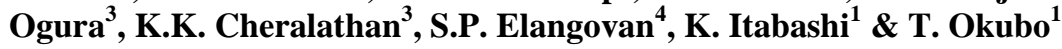 \\ ${ }^{1}$ Department of Chemical System Engineering, The University of Tokyo, Japan \\ ${ }^{2}$ Division of Inorganic and Physical Chemistry, Institut Teknologi Bandung, Indonesia \\ ${ }^{3}$ Institute of Industrial Science, The University of Tokyo, Japan \\ ${ }^{4}$ Nippon Chemical Industrial Co., Ltd., Tokyo, Japan \\ Email: okubo@chemsys.t.u-tokyo.ac.jp
}

\begin{abstract}
Hierarchically porous MFI zeolites (ZSM-5) have been synthesized by hydrothermal treatment in the presence of trialkoxysilylated-derivatives of nonionic poly(oxyethylene) alkyl ether or alkyl quaternary ammonium cation as mesopore-generating agent, along with tetrapropylammonium cation as zeolite structure-directing agent. Powder X-ray diffraction revealed that zeolites have been crystallized, and scanning electron microscopy showed rugged surface morphology that was quite different from conventional ZSM-5. The mesoporosity was confirmed by nitrogen adsorption-desorption measurement showing type IV isotherms with narrow distribution of mesopore diameters. The catalytic activity of these mesoporous ZSM-5 was tested in liquid-phase esterification of benzyl alcohol with hexanoic acid. The conversion of benzyl alcohol on mesoporous ZSM-5 prepared via cationic-templating route was almost $100 \%$, being much higher than on mesoporous ZSM-5 prepared with silylated nonionic surfactant as well as on conventional ZSM-5 with no mesopores. The presence of Brønsted acid sites, together with the mesopores, was responsible for this catalytic conversion, as confirmed by pyridine adsorption monitored by in situ infrared and ${ }^{27} \mathrm{Al}$ magic angle spinning nuclear magnetic resonance spectroscopy.
\end{abstract}

Keywords: catalysis; esterification; hierarchical pores; mesoporous zeolite; MFI zeolite; pyridine adsorption.

\section{$1 \quad$ Introduction}

A family of crystalline microporous materials comprising of zeolites and their analogues so far has 194 framework types with various topologies, elemental composition and pore diameters. In the case of zeolites, the largest aluminosilicate micropore diameter is $0.75 \mathrm{~nm}$, which is built from the 14membered-ring of tetrahedrally-coordinated silicon and aluminum atoms of CIT-5 (CFI framework) [1, 2]. In the siliceous form, UTD-1 (DON framework) has micropore diameter of $0.82 \mathrm{~nm}$, which is larger than that of CIT-5 [3].

Received July $5^{\text {th }}, 2010$, Revised December $14^{\text {th }}, 2010$, Accepted for publication December $15^{\text {th }}, 2010$. 
However, both of these zeolites have only one-dimensional pore topology that excludes their use as catalyst in the oil refining and petrochemical industries. Three-dimensional pore network of the silicogermanate zeolite analogue of ITQ-21 has $1.18 \mathrm{~nm}$ wide cavities with $0.74 \mathrm{~nm}$ wide windows equal to the framework of FAU zeolite (12-membered-ring), exhibiting high catalytic activity in oil refining [4]. Other zeolite analogues with large micropores include microporous aluminophosphate (e.g. VPI-5 [5], $\mathrm{AlPO}_{4}-8$ [6,7], JDF-20 [8] and gallophosphate, i.e. cloverite [9], ULM-5 [10]). However, synthesis of new zeolite with larger micropores and three-dimensional pore system still remains a difficult challenge, although they are highly demanded especially for enhancing the catalytic conversion of bulky compounds.

The generation of mesopores $(2-50 \mathrm{~nm})$ in zeolites may enhance the active sites accessibility, thus leading to the improvement of the catalytic performance. The hierarchically porous zeolites, hereafter denoted as mesoporous zeolites, have been synthesized by multistep methods such as hard-templating [11,12], dealumination [13], desilication [14,15] and exfoliation [16]. The mesoporosity in zeolite catalysts has been shown to solve the phenomena of slow diffusion and coke formation in the pores as a result of side catalytic reactions [17]. Onestep method to realize the synthesis of mesoporous zeolite was recently developed by employing silylated surfactant in combination with organic structure-directing agent (OSDA) [18]. Alkyltrimethylammonium-type, cationic surfactant bearing a trialkoxysilyl group acted as the mesopore-generating agent to produce various mesoporous zeolites (MFI, LTA, SOD and FAU) $[18,19]$. Furthermore, we have recently extended this method to the use of silylated nonionic surfactant and successfully obtained mesoporous MFI zeolites [20].

In this paper, we report the syntheses and catalytic properties of mesoporous ZSM-5, an aluminosilicate MFI zeolite. Trialkoxysilylated cationic and nonionic surfactants are used as the mesopore-generating agent in the hydrothermal synthesis of zeolite in the presence of OSDA. The products obtained from cationic and nonionic-templating route will be compared and detailed structural characterization is performed by powder X-ray diffraction, scanning electron microscopy, solid-state NMR and infrared spectroscopy. The catalytic activity of these mesoporous ZSM-5 is tested for the liquid-phase esterification of benzyl alcohol with hexanoic acid. The conversion of benzyl alcohol is compared to the one achieved with conventional ZSM-5 in order to examine the importance of generating mesoporosity in zeolites. 


\section{Experimental}

\subsection{Materials}

Sodium hydride $(\mathrm{NaH})$, dehydrated tetrahydrofuran (THF), allyl bromide $\left(\mathrm{CH}_{2}=\mathrm{CHCH}_{2} \mathrm{Br}\right)$, acetonitrile, aluminum hydroxide $\left(\mathrm{Al}(\mathrm{OH})_{3}\right)$, benzyl alcohol $\left(\mathrm{C}_{7} \mathrm{H}_{8} \mathrm{O}\right)$ were purchased from Wako. $\mathrm{NaH}$ was washed with heptane to remove the paraffin before use. Tetrapropylammonium hydroxide (TPAOH, $\left.\left(\mathrm{C}_{3} \mathrm{H}_{7}\right)_{4} \mathrm{NOH}\right)$, poly(oxyethylene) alkyl ether (Brij-76, $\mathrm{C}_{18} \mathrm{H}_{37} \mathrm{O}\left(\mathrm{C}_{2} \mathrm{H}_{4} \mathrm{O}\right)_{10} \mathrm{H}$ or simply $\left.\mathrm{C}_{18} \mathrm{EO}_{10}\right)$ and hexachloroplatinic(IV) acid hexahydrate $\left(\mathrm{H}_{2} \mathrm{PtCl}_{6} \cdot 6 \mathrm{H}_{2} \mathrm{O}\right)$, aluminum triisopropoxide $\left(\mathrm{Al}\left(\mathrm{OC}_{3} \mathrm{H}_{7}\right)_{3}\right)$ and hexanoic acid $\left(\mathrm{C}_{5} \mathrm{H}_{11} \mathrm{COOH}\right)$ were purchased from Sigma-Aldrich. Triethoxysilane $\left(\mathrm{HSi}\left(\mathrm{OC}_{2} \mathrm{H}_{5}\right)_{3}\right)$, tetraethyl orthosilicate (TEOS, $\left.\mathrm{Si}\left(\mathrm{OC}_{2} \mathrm{H}_{5}\right)_{4}\right)$ and $n$-nonane were purchased from TCI. Octadecyldimethyl(3-trimethoxysilylpropyl)ammonium chloride (TPAOC, $\left.\mathrm{C}_{18} \mathrm{H}_{37} \mathrm{~N}\left(\mathrm{CH}_{3}\right)_{2}\left(\mathrm{CH}_{2}\right)_{3} \mathrm{Si}(\mathrm{OMe})_{3} \mathrm{Cl}\right)$ was purchased from Gelest. Conventional $\mathrm{ZSM}-5$ with $\mathrm{Si} / \mathrm{Al}=12$ was provided from Tosoh Corporation (Japan).

\subsection{Synthesis of Nonionic Mesopore-Generating Agent (TES- $\mathrm{C}_{18} \mathrm{EO}_{10}$ )}

In the initial step, a nonionic surfactant consisting of a hydrophobic alkyl chain and a hydrophilic polyoxyethylene chain $\left(\mathrm{C}_{18} \mathrm{EO}_{10}\right)$ was activated with sodium hydride and reacted with allylbromide. The terminal $\mathrm{C}=\mathrm{C}$ double bond was then silylated with triethoxysilane to give triethoxysilyl-terminated nonionic surfactant (TES- $\left.\mathrm{C}_{18} \mathrm{EO}_{10}\right)$. Typically, a mixture of $\mathrm{C}_{18} \mathrm{EO}_{10}(10 \mathrm{~g}), \mathrm{NaH}$ (1.01 $\mathrm{g})$, and THF was stirred at room temperature for $4 \mathrm{~h}$. Allyl bromide $(1.43 \mathrm{ml})$ was then added and the mixture was further stirred for $24 \mathrm{~h}$. After the removal of unreacted allyl bromide and solvent under vacuum, THF was added to the residue and the undissolved solids were removed by filtration. Subsequently, the reaction with triethoxysilane $(4.91 \mathrm{ml})$ in the presence of Pt catalyst $(0.02 \mathrm{M}$ $\mathrm{H}_{2} \mathrm{PtCl}_{6}$ in acetonitrile) was performed at $353 \mathrm{~K}$ for $72 \mathrm{~h}$. A waxy solid was obtained after removing the solvent under vacuum. The formation of TES${ }_{18} \mathrm{EO}_{10}$ was confirmed by liquid-state ${ }^{13} \mathrm{C}$ NMR. Further information regarding this silylation reaction can be found in the literatures [21,22]. The crude product was used without further purification (quantitative yield).

\subsection{Synthesis of Hierarchically Porous Zeolites}

\subsubsection{Nonionic-Templating Route}

The preparation of mesoporous ZSM-5 via nonionic-templating route was performed by adding the nonionic mesopore-generating agent, TES- $\mathrm{C}_{18} \mathrm{EO}_{10}$, into a ZSM-5 seed solution followed by the hydrothermal reaction in a Teflonlined stainless steel autoclave at $393 \mathrm{~K}$ for $72 \mathrm{~h}$ under rotation at $20 \mathrm{rpm}$. 
TEOS, $\mathrm{Al}(\mathrm{OH})_{3}$ and TPAOH were used as silica source, aluminum source and OSDA, respectively. Typically, $0.05 \mathrm{~g}$ of $\mathrm{Al}(\mathrm{OH})_{3}$ and $3.16 \mathrm{~g}$ of TPAOH were dissolved in $7.57 \mathrm{~g}$ of distilled water and the mixture was stirred at room temperature for $5 \mathrm{~h}$. To this seed solution, a mixture of TES- $\mathrm{C}_{18} \mathrm{EO}_{10}(0.89 \mathrm{~g})$ and TEOS (4.43 g) was added under vigorous stirring. The final molar composition was $1 \mathrm{SiO}_{2}: 4 \mathrm{EtOH}: 0.017 \mathrm{Al}_{2} \mathrm{O}_{3}: 0.19$ TPAOH $: 25 \mathrm{H}_{2} \mathrm{O}: 0.05$ TES- $\mathrm{C}_{18} \mathrm{EO}_{10}$. The resulting product was washed with distilled water, recovered by centrifugation, and dried in an oven at $333 \mathrm{~K}$. The organic components were removed by calcination in air at $823 \mathrm{~K}$ for $8 \mathrm{~h}$ with a heating rate of $1 \mathrm{~K} / \mathrm{min}$. The resulting product is hereafter denoted as mesoporous ZSM-5(N).

\subsubsection{Cationic-Templating Route}

Mesoporous ZSM-5 was also synthesized via cationic-templating route following the method reported by Ryoo and co-workers [18] with some modifications. TPAOC as cationic mesopore-generating agent was added to a ZSM-5 seed solution prior to the hydrothermal treatment. The ZSM-5 seed solution was prepared by stirring $0.28 \mathrm{~g}$ of $\mathrm{Al}\left(\mathrm{O}^{\mathrm{i}} \mathrm{Pr}\right)_{3}$ as an aluminum source, $6.29 \mathrm{~g}$ of TPAOH, and $15.10 \mathrm{~g}$ of distilled water at room temperature for $4 \mathrm{~h}$. To this solution, a mixture of TPAOC (1.68 g) and TEOS (8.84 g) was added under vigorous stirring. The final molar composition was $1 \mathrm{SiO}_{2}: 4 \mathrm{EtOH}$ : $0.017 \mathrm{Al}_{2} \mathrm{O}_{3}: 0.19$ TPAOH : $25 \mathrm{H}_{2} \mathrm{O}: 0.05$ TPAOC. The hydrothermal reaction was performed at $393 \mathrm{~K}$ for $40 \mathrm{~h}$ under rotation at $20 \mathrm{rpm}$. The resulting product was washed with distilled water, recovered by centrifugation, and dried in an oven at $333 \mathrm{~K}$. The organic components were removed by calcination in air at $823 \mathrm{~K}$ for $8 \mathrm{~h}$ with a heating rate of $1 \mathrm{~K} / \mathrm{min}$. The resulting product is hereafter denoted as mesoporous ZSM-5(C).

\subsubsection{Generation of Proton By Ion-Exchange}

To eliminate the possibility of being contaminated with $\mathrm{Na}^{+}$as impurity cations, mesoporous ZSM-5(N) and ZSM-5(C) were treated with an aqueous $\mathrm{NH}_{4} \mathrm{Cl}$ solution. The concentration of $\mathrm{NH}_{4}{ }^{+}$was adjusted to be 100 times higher than that necessary to compensate for the framework charge. This treatment was carried out in a beaker at $353 \mathrm{~K}$ under stirring for $6 \mathrm{~h}$ and the procedure was repeated for 3 times. The solid was filtered and washed with water. The $\mathrm{NH}_{4}{ }^{+}-$ form products were finally converted into the $\mathrm{H}^{+}$-form by calcination at $773 \mathrm{~K}$ for $4 \mathrm{~h}$ and denoted as mesoporous HZSM-5. These samples were used for solid-state ${ }^{27} \mathrm{Al}$ MAS NMR measurement and catalytic testing. 


\subsection{Characterizations}

\subsubsection{Powder X-ray Diffraction}

Powder X-ray diffraction (XRD) patterns were recorded on a Bruker AXS M03X-HF22 diffractometer or on a Rigaku RINT 2000 diffractometer both with $\mathrm{Cu} \mathrm{K} \alpha$ radiation.

\subsubsection{Solid-State NMR Spectroscopy}

Solid-state ${ }^{27} \mathrm{Al}$ MAS NMR (JEOL CMX-300) spectra were recorded at a resonance frequency of $78.3 \mathrm{MHz}$ with a spinning rate of $10 \mathrm{kHz}$, a pulse width of $1.0 \mu \mathrm{s}$ and a recycle delay of $5 \mathrm{~s} .1 \mathrm{M}$ aluminum nitrate $\left(\mathrm{Al}\left(\mathrm{NO}_{3}\right)_{3}\right)$ was used as a standard which appears at $0 \mathrm{ppm}$.

\subsubsection{Scanning Electron Microscopy}

Field-emission scanning electron microscopy (FE-SEM) images were taken by Hitachi S-4800 at an accelerating voltage of $1 \mathrm{kV}$.

\subsubsection{Nitrogen Adsorption-Desorption Isotherm}

Nitrogen adsorption-desorption isotherms were obtained with an Autosorb-1 instrument (Quantachrome Instruments) at $77 \mathrm{~K}$. Samples were preheated at $150{ }^{\circ} \mathrm{C}$ for $6 \mathrm{~h}$ under vacuum. The Brunauer-Emmett-Teller (BET) surface areas were calculated from the adsorption branch of the isotherms in the relative pressure range from 0.06 to 0.18 . Mesopore size distributions were calculated by Barrett-Joyner-Halenda (BJH) method using adsorption branch.

\subsubsection{Pyridine Adsorption Monitored By In Situ Infrared (IR) Spectroscopy}

The samples were compacted into self-supporting pellets and activated under vacuum with $p=10^{-2}$ mbar at $673 \mathrm{~K}$ for $1 \mathrm{~h}$. The spectrum of the activated sample was recorded by an infrared (IR) spectrometer (Nicolet) prior to the adsorption of pyridine. The pyridine in a small quantity (up to 1 mbar pressure) was introduced through glass vacuum cells into the samples. Before recording the spectra of adsorbed samples, pyridine was outgassed at $423 \mathrm{~K}$. To directly compare the surface coverage of the adsorbed species, all spectra were normalized using the overtone and combination vibrations of the MFI materials between 2105 and $1740 \mathrm{~cm}^{-1}$. 


\subsubsection{Catalytic Testing of Hierarchically Porous Zeolite: Esterification of Benzyl Alcohol With Hexanoic Acid}

Liquid-phase esterification on hierarchically porous ZSM-5 was carried out under nitrogen atmosphere, using a batch reactor (round-bottom flask) equipped with a reflux condenser and a magnetic stirrer. Benzyl alcohol $(4.10 \mathrm{~g}, 0.037$ $\mathrm{mol})$, hexanoic acid $(4.80 \mathrm{~g}, 0.041 \mathrm{~mol})$, toluene $(18 \mathrm{~g})$, and $n$-nonane $(7.51 \mathrm{~g})$ were mixed, and each reaction $(4.63 \mathrm{~g})$ was carried out with or without catalyst $(0.10 \mathrm{mg})$ at $378 \mathrm{~K}$ for $4 \mathrm{~h}$. Toluene and $n$-nonane were used as a solvent and an internal standard, respectively. After the reaction mixture was cooled down, the catalysts were removed by using syringe filter (Whatman $0.2 \mu \mathrm{m}$ PVDF) that is connectable to the disposable $6 \mathrm{ml}$ syringe (NORM-JECT ${ }^{\circledR}$, Henke Sass Wolf). The liquid phase was diluted 12.5 times with toluene and injected as much as $5 \mu \mathrm{L}$ using micro syringe (ITO MS-NG05) into the gas chromatograph-mass spectrometer (Shimadzu GC-17A/GCMS-QP5050) equipped with a weak polar capillary column $(1.5 \mu \mathrm{m} \times 30 \mathrm{~mm} \times 0.25 \mathrm{~mm}, 5 \%$ phenyl-95\% methylpolysiloxane, GL Sciences, InertCap ${ }^{\circledR 5)}$ ). The conversion of benzyl alcohol and selectivity for the ester product over $\mathrm{H}^{+}$-form hierarchically porous zeolites as catalyst were quantitatively observed. Conventional $\mathrm{H}^{+}$-ZSM-5 was used as catalyst for comparison after applying ion exchange procedure described in 2.3.3.

\section{$3 \quad$ Results and Discussion}

Figure 1 shows XRD patterns of as-synthesized, calcined and $\mathrm{H}^{+}$-formed products prepared via nonionic and cationic-templating routes. The crystallization of MFI zeolites has been confirmed. The peak corresponding to mesoscale ordering is also observed at low angle only in the case of mesoporous ZSM-5(C) (Figure 1 right). A single, broad peak with $d$-spacing of $5.6 \mathrm{~nm}(2 \theta=$ $1.5^{\circ}$ ) (data not shown) may point to the formation of a wormhole-like mesostructure. However, mesoporous ZSM-5(N) does not exhibit any diffraction peaks at low angle (Figure 1 left). In the case of hierarchical zeolite system, the growth of crystalline phase generally inhibits the generation of mesopores because mesoporous silica, with amorphous framework, is thermodynamically less-stable. The crystallinity of mesoporous ZSM-5(N) is higher than in mesoporous ZSM-5(C), which can be simply observed from the presence of amorphous phase in the latter samples, as suggested by the broad peak centered at $23^{\circ}$. In the case of ZSM-5(N), the increase of zeolite crystalline phase probably led to the formation of an ill-ordered mesostructure showing no diffraction peak at low angle (Figure 1 left). It is speculated that the wormholelike mesostructure with lower crystallinity of MFI can be obtained via nonionictemplating route by controlling the hydrothermal conditions. This is supported 
by our recent report on the synthesis of mesoporous siliceous MFI zeolite (silicalite-1) with a wormhole-like mesostructure with $d=7.5 \mathrm{~nm}$ using TES$\mathrm{C}_{16} \mathrm{EO}_{10}[20]$.

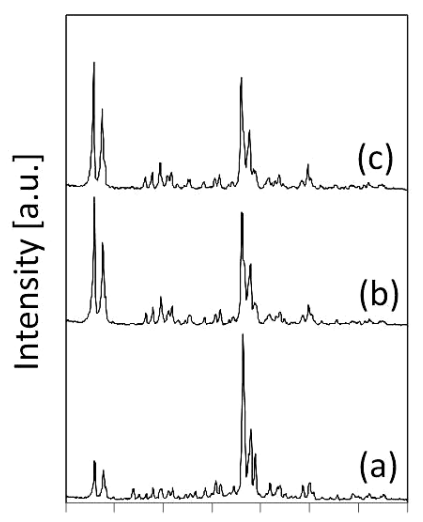

$\begin{array}{llllllll}5 & 10 & 15 & 20 & 25 & 30 & 35 & 40\end{array}$ $2 \theta\left[^{\circ}\right]$

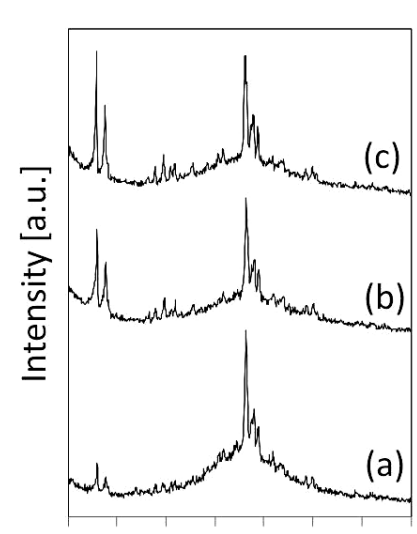

$5 \quad 1015202530 \quad 3540$ $2 \theta\left[^{\circ}\right]$

Figure 1 Powder XRD patterns of mesoporous ZSM-5(N) (left) and ZSM-5(C) (right) synthesized by nonionic- and cationic-templating routes, respectively: (a) as-synthesized, (b) calcined, and (c) $\mathrm{H}^{+}$-formed.

The isomorphous substitution of $\mathrm{Si}$ with $\mathrm{Al}$ atom during the hydrothermal synthesis was confirmed by ${ }^{27} \mathrm{Al}$ MAS NMR spectroscopy of the $\mathrm{H}^{+}$-formed samples (Figure 2). The peak at around $60 \mathrm{ppm}$, assigned to tetrahedrallycoordinated $\mathrm{Al}$ atoms, appears in the spectra of both of the mesoporous ZSM-5 samples, suggesting the formation of Brønsted acid sites in the framework. However, in the case of mesoporous ZSM-5(N), the hexacoordinated, extraframework aluminum (at $0 \mathrm{ppm}$ ) is dominant compared to the tetrahedral $\mathrm{Al}$ species. This octahedrally-coordinated aluminum may act as Lewis acid sites located in the non-framework of MFI. We have evidences that the assynthesized sample prepared via nonionic-templating route has only tetrahedrally-coordinated $\mathrm{Al}$ atoms [23,24]. From this observation, the dealumination process seems to take place during the organic removal or proton exchange.

We speculate that the crystallization of zeolite in the presence of silylated nonionic surfactant may lead to the substitution of Al mostly near the pore mouth, hence creating instability against the post synthetic treatment. In contrast, mesoporous zeolite synthesized via cationic-templating route provides a stable aluminosilicate framework against the post-synthetic treatment such as calcination and proton exchange. The presence of such cationic mesoporegenerating agent may give fine distribution of $\mathrm{Al}$ in the framework of zeolite 
because negatively-charged $\mathrm{Al}$ should somewhat be compensated by the ammonium cation in the surfactant tail since the formation of wormhole-like micelle principally gives the opportunity to locate these ions close to the zeolite nuclei. On the contrary, the nonionic mesopore-generating agent cannot provide this compensating electrostatic effect and fundamental study will be proposed to unravel the dealumination process.

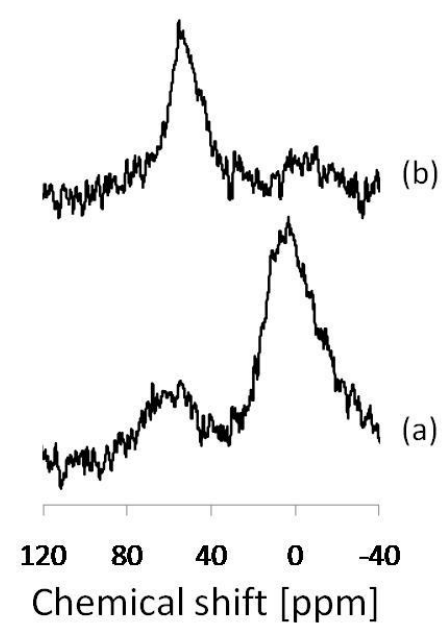

Figure 2 Solid-state ${ }^{27} \mathrm{Al}$ MAS NMR spectra of (a) mesoporous ZSM-5(N) and (b) mesoporous ZSM-5(C) both in the $\mathrm{H}^{+}$-form.

FE-SEM observation revealed that the morphologies of these mesoporous MFI zeolites were quite different from the coffin-type crystal morphology generally observed for conventional MFI zeolite. As shown in Figure 3, both mesoporous ZSM-5(N) and ZSM-5(C) show rugged surface morphologies, suggesting that these particles consist of small MFI crystals with intercrystal mesopores, similar to the case of mesoporous silicalite-1 [20].
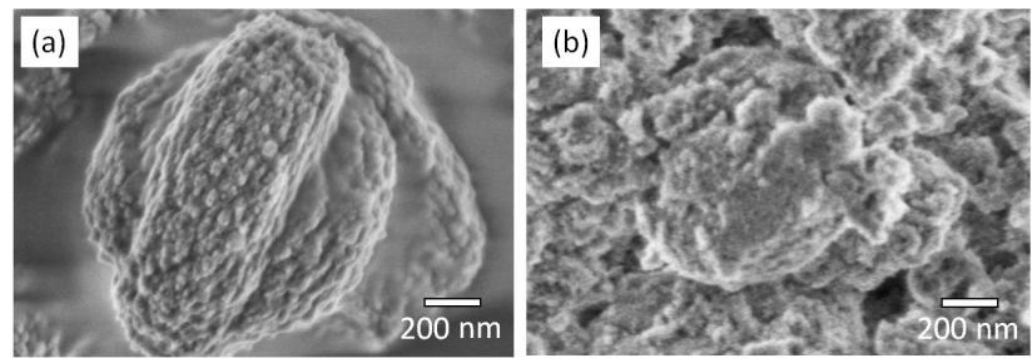

Figure 3 FE-SEM images of (a) mesoporous ZSM-5(N) and (b) mesoporous ZSM-5(C). 

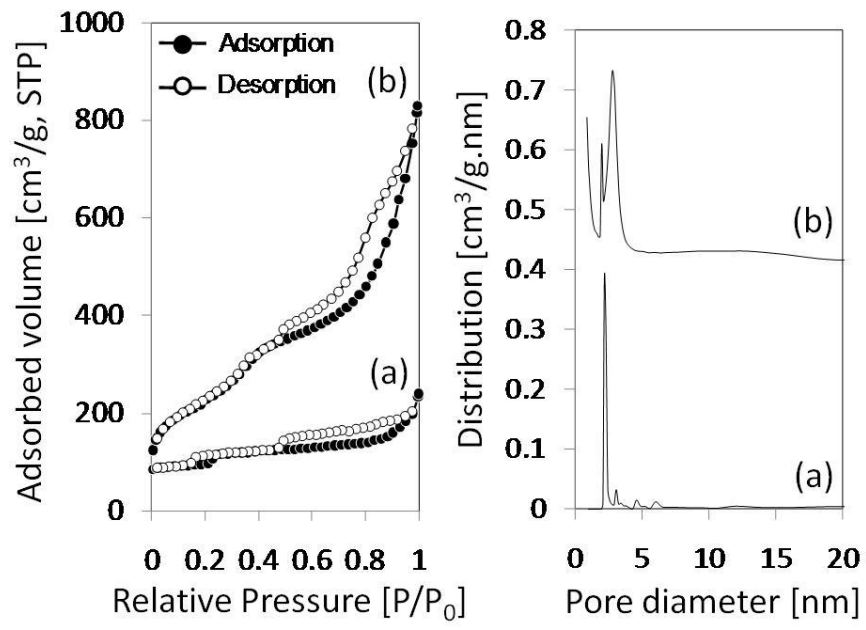

Figure 4 Nitrogen adsorption-desorption isotherms (left) and BJH pore size distribution (right) of (a) mesoporous ZSM-5(N) and (b) mesoporous ZSM-5(C). The pore size distribution curve for ZSM-5(C) was vertically offset by $0.4 \mathrm{~cm}^{3} \mathrm{~g}^{-1}$ $\mathrm{nm}^{-1}$.

The mesoporosity was confirmed by nitrogen adsorption-desorption measurement (Figure 4, left). The isotherms of mesoporous ZSM-5(N) and ZSM-5(C) show type IV due to the capillary condensation in mesopores. Table 1 summarizes the surface and pore characteristics of mesoporous ZSM-5 samples. Mesoporous ZSM-5(C) shows higher BET surface area and mesopore volume than mesoporous $\mathrm{ZSM}-5(\mathrm{~N})$. It is interesting to note that the size distribution of mesopores is relatively narrow for these mesoporous ZSM-5 (Figure 4, right). The pore sizes estimated by BJH method [25] are comparable for both samples. In general, the mesoporosity and its pore size depend not only on the type of the surfactants, but also on the size of the surfactants, nature of precursors and other synthesis conditions (e.g. acidic or basic, surfactant/Si ratio, temperature, time, etc). For example, the resulting mesopore size of ZSM$5(C)$ has a slight difference from the results shown in ref. [18]. The discrepancy might rely on the synthesis condition particularly the hydrothermal temperature and time, in spite of utilizing the same mesopore-generating agent.

Table 1 Surface and pore characteristics of mesoporous ZSM-5 samples.

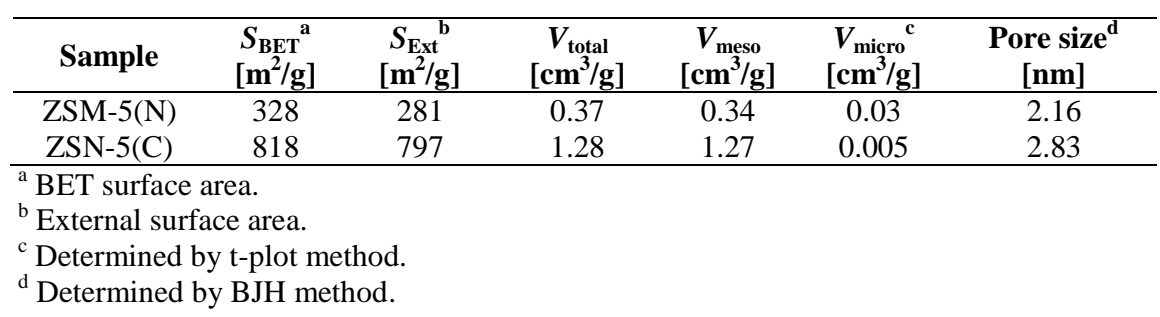


The acidity of mesoporous ZSM-5 samples in the $\mathrm{H}^{+}$-form was probed by pyridine adsorption and analyzed using IR spectroscopy. Conventional ZSM-5 was also investigated for comparison. Figure 5 shows the selected regions of the IR spectra of the activated ZSM-5 samples before and after pyridine adsorption. In the spectra before pyridine adsorption (Figure 5, left), peaks at $3743 \mathrm{~cm}^{-1}$ assigned to terminal hydroxyl $(\mathrm{SiOH})$ groups are observed for all of the samples. For conventional ZSM-5, the peak at $3608 \mathrm{~cm}^{-1}$, assigned to the bridging hydroxyl (SiOHAl) groups (Brønsted acid site), is clearly observed.

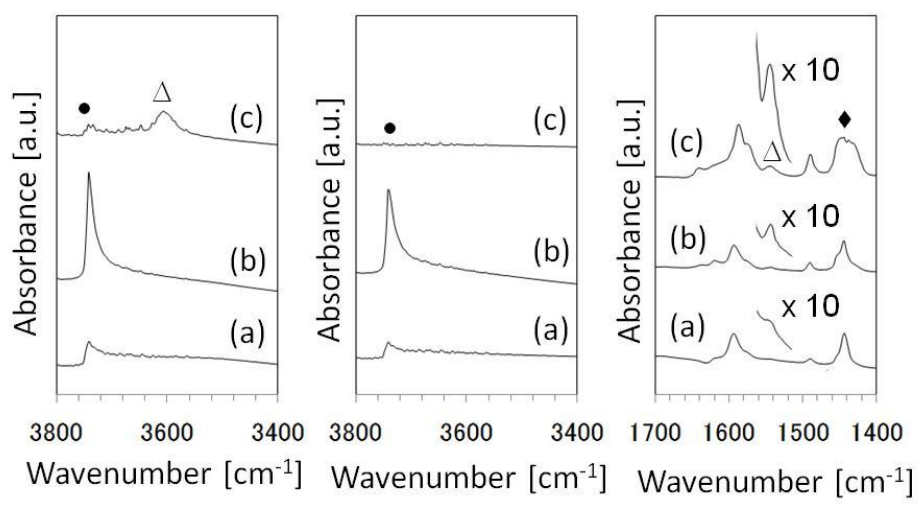

Figure 5 FT-IR spectra of (a) mesoporous ZSM-5(N), (b) mesoporous ZSM5(C), and (c) conventional ZSM-5: (left) the $3400-3800 \mathrm{~cm}^{-1}$ region before pyridine adsorption, (middle) the same region after pyridine adsorption with evacuation, and (right) the $1400-1700 \mathrm{~cm}^{-1}$ region after pyridine adsorption with evacuation. The symbol $\bullet$ and $\Delta$ correspond to $\mathrm{SiOH}$ and SiOHAl (Brønsted acid sites), respectively. The symbol $\bullet$ corresponds to Lewis acid sites.

The adsorption of pyridine gives the reduction of these hydroxyl group peaks (Figure 5, middle) and the presence of new peaks that correspond to Brønsted and Lewis acid sites (Figure 5, right). The peak of pyridine molecules adsorbed on Brønsted acid sites in the form of pyridinium ion appears at $1544 \mathrm{~cm}^{-1}$, while the peak for pyridine adsorbed on Lewis acid sites appears at $1454 \mathrm{~cm}^{-1}$ (Figure 5, right). Mesoporous ZSM-5(C) contains more Brønsted acid sites than mesoporous $\mathrm{ZSM}-5(\mathrm{~N})$ despite the same $\mathrm{Si} / \mathrm{Al}$ ratio in the initial precursor prior to hydrothermal treatment. This is in line with the ${ }^{27} \mathrm{Al}$ MAS NMR result showing that tetrahedrally-coordinated $\mathrm{Al}$ species is more dominant in mesoporous ZSM-5(C).

The catalytic activity of mesoporous ZSM-5 in the $\mathrm{H}^{+}$-form was tested in the liquid phase esterification of benzyl alcohol with hexanoic acid. Table 2 summarizes the catalytic conversion of benzyl alcohol. This reaction does not proceed in the absence of catalyst at least within the reaction time of $4 \mathrm{~h}$ at 378 
K. Notably, mesoporous HZSM-5(C) converted nearly all benzyl alcohol into the ester as a product, whereas mesoporous HZSM-5(N) could not fully convert benzyl alcohol. In fact, the two catalysts have different amounts of Brønsted acid sites, but have comparable Lewis acid sites (Figure 4, left). The less amount of Brønsted acid sites in mesoporous HZSM-5 $(\mathrm{N})$ prevents the good catalytic conversion but mesoporous HZSM-5(C) with a relatively large amount of Brønsted acid sites was shown to be an optimized catalyst for the liquidphase esterification of benzyl alcohol with hexanoic acid. It seems that Brønsted acidity along with mesoporosity play a crucial role in converting the benzyl alcohol since the conventional HZSM-5 with a relatively large amount of Brønsted acid sites does not show high catalytic activity due to the absence of mesoporosity.

Table 2 Catalytic activity of hierarchically porous HZSM-5 in comparison with the conventional HZSM-5.

\begin{tabular}{ccc}
\hline Entry & Catalyst & Conversion [\%] \\
\hline 1 & No & 0 \\
2 & Mesoporous HZSM-5(N) & 20 \\
3 & Mesoporous HZSM-5(C) & 99 \\
4 & HZSM-5 & 13 \\
\hline
\end{tabular}

The ester product was confirmed to be benzylpentanoate by GCMS, which is a useful compound due to the fruity odor (apple skin), therefore highly demanded by the food industries. Srivastava and co-workers [26] reported similar reaction using mesoporous HZSM-5 catalyst synthesized via cationic-templating route, but benzylhexanoate was obtained as the product instead of benzylpentanoate. The disagreement with our result may be due to the difference in the mesopore size of the catalyst. In their case, mesopore diameter of $5.2 \mathrm{~nm}$ was generated by using shorter surfactant tail (alkyl chain of 16) in the silylated cationic sufactant and this perhaps promotes the production of longer ester instead of shorter ester. The production of shorter ester may be preceded after cracking the esterifying agent (hexanoic acid) during the reaction. Generally, when zeolites are used as catalyst, the water formed as a result of the esterification reaction could lead to the deactivation or pore mouth blockage of the catalyst. This assumption may be used to explain the cracking phenomenon in the esterification of benzyl alcohol with hexanoic acid. However, further investigation regarding the effect of pore size and water poisoning on the formation of ester product is indeed necessary. These preliminary catalytic results shall be more explored in order to understand the selectivity, mechanism and active center responsible for the efficient conversion of liquid-phase esterification catalyzed by mesoporous zeolites. 


\section{Conclusion}

The silylated cationic and nonionic surfactants have been succesfully used as mesopore-generating agents for synthesizing hierarchically porous MFI zeolites (ZSM-5). The morphologies of both mesoporous ZSM-5 show rugged surface of small MFI crystals with intercrystal mesopores. We have demonstrated that the hierarchically porous zeolites show narrow mesoporosity which can be useful for liquid-phase esterification of benzyl alcohol with hexanoic acid. By using cationic-derived mesoporous ZSM-5, all benzyl alcohol can be nearly converted into ester as product, whereas the nonionic-derived mesoporous HZSM-5 could not optimally convert the benzyl alcohol. The presence of Brønsted acid sites along with the mesoporosity supports this catalytic conversion. In situ IR spectroscopy monitoring the adsorption of pyridine and ${ }^{27} \mathrm{Al}$ MAS NMR spectroscopy were used to characterize the acidity and the nature of $\mathrm{Al}$ species in the zeolite framework/extra-framework.

\section{Acknowledgements}

This work is partially supported by the Grant-in-Aid for Scientific Research from the Ministry of Education, Culture, Sports, Science and Technology (MEXT), Japan. We acknowledge Prof. S. Maruyama, Dr. S. Chiashi, Dr. E. Einarsson and Mr. T. Moteki (The University of Tokyo) for providing access to the SEM instrument. RRM acknowledges Dr. L. Yuliati (Ibnu Sina Institute for Fundamental Science Studies, Universiti Teknologi Malaysia) and Dr. K. Takanabe (The University of Tokyo) for fruitful discussion.

\section{References}

[1] Yoshikawa, M., Wagner, P., Lovallo, M., Tsuji, K., Takewaki, T., Chen, C. Y., Beck, L. W., Jones, C., Tsapatsis, M., Zones, S.I. \& Davis, M.E., Synthesis, Characterization, and Structure Solution of CIT-5, A New, High-Silica, Extra-Large-Pore Molecular Sieve, J. Phys. Chem. B, 102(37), 7139-7147, 1998.

[2] Wagner, P., Yoshikawa M., Lovallo, M., Tsuji, K., Tsapatsis, M. \&, Davis, M.E., CIT-5: A High-Silica Zeolite with 14-Ring Pores, Chem. Commun., 2179-280, 1997.

[3] Freyhardt, C.C., Tsapatsis, M., Lobo, R.F., Balkus, K.J. \& Davis, M.E., A High-Silica Zeolite with a 14-Tetrahedral-Atom Pore Opening, Nature, 381(6580), 295-298, 1996.

[4] Corma, A., Diaz-Cabanas, M., Martinez-Triguero, J., Rey, F. \& Rius, J., A Large-Cavity Zeolite with Wide Pore Windows and Potential as an Oil Refining Catalyst, Nature, 418(6897) ,514-517, 2002. 
[5] Davis, M.E., Saldarriaga, C., Montes, C., Garces, J. \& Crowder, C., A Molecular-Sieve with 18-Membered Rings, Nature, 331(6158), 698-699, 1988.

[6] Dessau, R.M., Schlenker, J.L. \& Higgins, J.B., Framework Topology of $\mathrm{AlPO}_{4}-8$ - The 1st 14-Ring Molecular-Sieve, Zeolites, 10(6), 522-524, 1990.

[7] Vogt, E.T.C. \& Richardson, J.W., The Reversible Transition of The Molecular-Sieve VPI-5 into $\mathrm{AlPO}_{4}-8$ and the Structure of $\mathrm{AlPO}_{4}-8$, J. Solid State Chem., 87(2), 469-471, 1990.

[8] Jones, R.H., Thomas, J.M., Chen, J.S., Xu, R.R., Huo, Q.S., Li, S.G., Ma, Z.G. \& Chippindale, A.M., Structure of an Unusual Aluminum Phosphate $\left(\left[\mathrm{Al}_{5} \mathrm{P}_{6} \mathrm{O}_{24} \mathrm{H}\right]^{2-} 2\left[\mathrm{~N}\left(\mathrm{C}_{2} \mathrm{H}_{5}\right)_{3} \mathrm{H}\right]^{+} .2 \mathrm{H}_{2} \mathrm{O}\right) \quad J D F-20$ with Large Elliptical Apertures, J. Solid State Chem., 102(1), 204-208, 1993.

[9] Estermann, M., McCusker, L.B., Baerlocher, C., Merrouche, A. \& Kessler, H., A Synthetic Gallophosphate Molecular-Sieve with A 20Tetrahedral-Atom Pore Opening, Nature, 352(6333), 320-323, 1991.

[10] Loiseau, T. \& Ferey, G., Oxyfluorinated Microporous Compounds, VII. Synthesis And Crystal-Structure And ULM-5, A New Fluorinated Gallophosphate $\mathrm{Ga}_{16}\left(\mathrm{PO}_{4}\right)_{14}\left(\mathrm{HPO}_{4}\right)_{2}(\mathrm{OH})_{2} \mathrm{~F}_{7},\left[\mathrm{H}_{3} \mathrm{~N}\left(\mathrm{CH}_{2}\right)_{6} \mathrm{NH}_{3}\right]_{4}, 6 \mathrm{H}_{2} \mathrm{O}$ with 16-Membered Rings And Both Bonding And Encapsulated F, J. Solid State Chem., 111(2), 403-415, 1994.

[11] Fan, W., Snyder, M.A., Kumar, S., Lee, P.S., Yoo, W.C., McCormick, A.V., Penn, R.L. \& Stein, A., Tsapatsis, M., Hierarchical nanofabrication of microporous crystals with ordered mesoporosity, Nat. Mater., 7(12), 984-991, 2008.

[12] Li, H.C., Sakamoto, Y., Liu, Z., Ohsuna, T., Terasaki, O, Thommes, M. \& Che, S.N., Mesoporous silicalite-1 zeolite crystals with unique pore shapes analogous to the morphology, Microporous Mesoporous Mater., 106(1-3), 174-179, 2007.

[13] Corma, A., Melo, F.V. \& Rawlence, D.J., Effect of The Nonuniform Dealumination on The Acidity and Catalytic Activity of Faujasite, Zeolites, 10(7), 690-694, 1990.

[14] Groen, J.C., Moulijn, J.A., Pérez-Ramiréz, J., Desilication: on the Controlled Generation of Mesoporosity in MFI zeolites, J. Mater. Chem., 16(22), 2121-2131, 2006.

[15] Ogura, M., Shinomiya, S.Y., Tateno, J., Nara, Y., Nomura, M., Kikuchi, E. \& Matsukata, M., Alkali-treatment technique - New Method for Modification of Structural and Acid-Catalytic Properties of ZSM-5 Zeolites, Appl. Catal. A, 219(1-2), 33-43, 2001.

[16] Corma, A., Fornes, V., Pergher, S.B., Maesen, T.L.M. \& Buglass, J.G., Delaminated Zeolite Precursors as Selective Acidic Catalysts, Nature, 396(6709), 353-356, 1998. 
[17] Corma, A., From Microporous to Mesoporous Molecular Sieve Materials and their Use in Catalysis, Chem. Rev., 97(6), 2373-2419, 1997.

[18] Choi, M., Cho, H.S., Srivastava, R., Venkatesan, C., Choi, D.H. \& Ryoo, R., Amphiphilic Organosilane-Directed Synthesis of Crystalline Zeolite with Tunable Mesoporosity, Nat. Mater., 5(9), 718-723, 2006.

[19] Choi, M., Lee, D.H., Na, K., Yu, B.W. \& Ryoo, R., High Catalytic Activity of Palladium(II)-Exchanged Mesoporous Sodalite and NaA Zeolite for Bulky Aryl Coupling Reactions: Reusability under Aerobic Conditions, Angew. Chem. Int. Ed., 48(20), 3673-3676, 2009.

[20] Mukti, R.R., Hirahara, H., Sugawara, A., Shimojima, A., Okubo, T., Direct Hydrothermal Synthesis of Hierarchically Porous Siliceous Zeolite by Using Alkoxysilylated Nonionic Surfactant, Langmuir, 26(4), 27312735, 2010.

[21] Urata, C., Yamauchi, Y., Mochizuki, D. \& Kuroda, K., One-pot Preparation of Mesoporous Silica Particles Having Mesopore Surface Functionalized with Poly(propylene oxide) chains, Chem. Lett., 36(7), 850-851, 2007.

[22] Yamamoto, S., Miyamoto, T., Kokubo, T. \& Nakamura, T., Preparation of Polymer-Silicate Hybrid Materials Bearing Silanol Groups and the Apatite Formation on/in the Hybrid Materials, Polym. Bull., 40(2-3), 243-250, 1998.

[23] Hirahara, H., MSc. Thesis, The University of Tokyo, 2008.

[24] Mukti, R.R., Hirahara, H., Sugawara, A., Shimojima, A., Okubo, T., unpublished results.

[25] Sing, K.S.W., Everett, D.H., Haul, R.A.W., Moscou, L., Pierotti, R.A., Rouquerol, J. \& Siemieniewska, T., Reporting Physisorption Data For Gas Solid Systems with Special Reference To The Determination Of Surface-Area And Porosity (Recommendations 1984), Pure Appl. Chem., 57(4), 603-619, 1985.

[26] Srivastava, R., Choi, M. \& Ryoo, R., Mesoporous Materials with Zeolite Framework: Remarkable Effect of the Hierarchical Structure for Retardation of Catalyst Deactivation, Chem. Commun., 4489-4491, 2006. 